P. 65-88 Denize Elena Garcia da Silva

\title{
DISCURSOS DO ECOLOGISMO E ECOLOGIA HUMANA: CAMINHOS ENTRE ETNOGRAFIA CRÍTICA E ECOLINGUÍSTICA
}

\author{
(Discourses from ecologism and human ecology: \\ paths between critical ethnography and 'ecolinguistics') \\ Denize Elena Garcia da Silva ${ }^{1}$ \\ (Universidade de Brasília - UnB)
}

\begin{abstract}
Based on studies related to social practices, configured in discursive practices which concern the policing of human activities' forms in relation to the environment, this paper aims to draw a parallel between the discourse of ecologism, a movement emerged as a reaction to economic growth, and that can be characterized as a discourse of human ecology. This is a comparative route, based on a theoretical triangulation that has at its main apex Critical Discourse Analysis (CDA), on the slope of Norman Fairclough (2001, 2003), flanked by critical ethnography, in the molds of Jim Thomas (1993), and by the study of the relationship between language and the environment, configured in 'Ecolinguistics', current developed in Brazil by Hildo Couto (2007). Anchored in this triad, I seek to discuss the theme of ecological issues from the representational meanings of discourse, tied to transitivity of the language proposed by Halliday (1994). The analytical focus of discussion is permeated by theoretical model ('Mandala of experience') that involves from the inner world of abstract relations (be) going through the physical world (material actions) of social practices (cohabitation, changes within the community) to reach the world of consciousness (need for life preservation, including the environment). The

1. Doutora em Linguística Hispánica pela Universidad Nacional Autónoma de México (1996) e Mestra em Linguística pela Universidade de Brasília (1991). Realizou estágio pós-Doutoral (2009), com o auxílio da CAPES, na Faculdade de Letras da Universidade de Lisboa (FLUL) e desenvolveu atividades de pesquisa junto ao Instituto de Linguística Teórica e Computacional (ILTEC) de Portugal (2009). É Pesquisadora Colaboradora Plena junto à Universidade de Brasília, onde atua como docente desde 1987.
\end{abstract}


first results signify a contribution in that which is displayed, rather than reflection, serves to encourage transformative discursive practices in terms of benefit (s) to a new social order.

Keywords: discourses of ecologism, human ecology, critical ethnography, ecolinguistics

\section{RESUMO}

Com base em estudos voltados para práticas sociais, configuradas em práticas discursivas concernentes ao policiamento de formas de atividades humanas com relação ao meio ambiente, o artigo tem como objetivo traçar um paralelo entre o discurso do ecologismo, movimento surgido como reação ao crescimento econômico, e o que se pode caracterizar como discurso da ecologia humana. Trata-se de um percurso comparativo, balizado por uma triangulação teórica que tem em seu vértice principal a Análise de Discurso Crítica (ADC), na vertente de Norman Fairclough (2001, 2003), ladeado pelo enfoque da etnografia crítica, nos moldes de Jim Thomas (1993), e pelo estudo das relações entre a língua e o meio ambiente, configurado na Ecolinguística, corrente desenvolvida no Brasil por Hildo Couto (2007). Ancorada nessa tríade, busco discutir a temática das questões ecológicas a partir dos significados representacionais do discurso, atrelados à transitividade da linguagem proposta por Halliday (1994). O enfoque analítico da discussão é permeado por um modelo teórico ('mandala da experiência') que envolve desde o mundo interior das relações abstratas (ser), passando pelo mundo físico (ações materiais) das práticas sociais (convivência, mudanças no âmbito da coletividade) até chegar ao mundo da consciência (necessidade de preservação da vida, o que inclui o entorno). Os primeiros resultados alcançados significam uma contribuição na medida em que o que for apresentado, mais que reflexão, servir para incentivar práticas discursivas transformadoras em termos de benefício(s) para uma nova ordem social.

Palavras-chave: discursos do ecologismo, ecologia humana, etnografia crítica, ecolinguística

\section{Introdução}

$\mathrm{O}$ artigo tem como objetivo traçar um paralelo comparativo entre discursos do ecologismo, enquanto movimento histórico de 
natureza ambientalista, e a ecologia humana, através do estudo das relações entre a língua e o meio ambiente (ecolinguística), mediadas pelo discurso como prática social, associado à gramática da experiência (interioridade do sistema linguístico). O propósito subjacente ao estudo é contribuir para uma reflexão crítica com base em práticas discursivas, que permeiam práticas sociais concernentes ao policiamento de formas de atividades humanas, voltadas para o denominado 'desenvolvimento sustentável'.

O trabalho encontra-se dividido em quatro partes, além da introdução ora apresentada. Na primeira, exponho os pressupostos teóricos básicos da Análise de Discurso Crítica (ADC), na vertente de Fairclough (2001, 2003), associados à teoria da linguagem desenvolvida por Halliday $(1994,2003)$. Na segunda parte, que envolve uma breve discussão teórica sobre a etnografia crítica, nos moldes de Thomas (1993), explicito o que vem a ser a ecolinguística, conforme modelo teórico defendido por Couto (2007). Na terceira parte, ancorada nessa tríade teórica, busco traçar um percurso de natureza crítica - com enfoque na temática pertinente a questões ecológicas -, balizado pelos significados do discurso (Fairclough, 2003), atrelados às macrofunções propostas por Halliday (1994), com ênfase no significado experiencial da linguagem, ou seja, na experiência de mundo do falante e de suas escolhas no sistema de transitividade da língua, o que envolve três componentes: processos verbais, participantes e circunstâncias de um evento comunicativo. O foco inicial da discussão teórica recai na natureza dos processos verbais, cuja fonte de energia - emanada de centros geradores de nosso mundo conceptual e linguístico -, associo metaforicamente a uma 'mandala' (Silva, 2011). Trata-se da 'mandala da experiência', abstração teórica com a qual busco discutir a possibilidade de um caminho de aproximação ao estudo das relações entre a língua e o meio ambiente, configurado na Ecolinguística. Na última parte, com base no percurso de três momentos históricos do ecologismo, bem como na síntese dos resultados publicados sobre o evento do Rio +20 , teço comentários pertinentes à intertextualidade, em sua faceta de interdiscursividade, que perpassa discursos do ecologismo. 


\section{Enlaces teóricos}

Esta seção envolve a interação dialógica que existe entre a Análise de Discurso Crítica (ADC), na vertente de Fairclough (2001, 2003, 2010) e a teoria da linguagem desenvolvida por Halliday (1994, 2003). Procuro mostrar que o estudo da linguagem, integrado ao enfoque de outras formas sociais de semiose, bem como à interioridade do sistema linguístico, permite analisar a sua exterioridade (discurso) de maneira crítica.

\subsection{Análise de Discurso Crítica}

Inicialmente, cabe enfatizar que as práticas sociais se concretizam a partir de práticas discursivas, razão pela qual os pressupostos teóricos da Análise de Discurso Crítica (ADC) balizam os caminhos das reflexões aqui apresentadas. De acordo com Fairclough (2012, p. 94), "toda prática é uma articulação de diversos elementos sociais em uma configuração relativamente estável, sempre incluindo o discurso". Nessa perspectiva, o discurso é sempre considerado como prática social (não individual) e a linguagem como um objeto historicamente produzido e interpretado em termos de sua relação com estruturas de poder e ideologia. Na esteira do pensamento de Fairclough (2001, 2003, 2010), pode-se reconhecer que práticas sociais, enquanto atividades culturais mais amplas, implicam uma relação dialética com a variação e a mudança nos usos linguístico-discursivos, o que nos leva a indagar como são produzidos pelas sociedades tanto os efeitos benéficos (uma economia ecológica que leva em consideração a natureza, o respeito ao meio ambiente), como os maléficos (conflitos ambientais, bem como a degradação causada pelo crescimento econômico desordenado que gera desigualdade social e multiplica a pobreza).

$\mathrm{Na}$ vertente crítica brasileira, enquanto analistas de discurso, cientes da variabilidade entre práticas e heterogeneidade, bem como entre processos de mudança histórica, conduzimos pesquisas linguísticas em torno de temas que vão desde práticas discursivas 
de natureza educacional, política, jurídica, como também midiática, passando pelas implicações de poder, ideologia e identidades sociais do mundo pós-moderno até questões de luta e conflito social (Silva, 2012). A vertente inglesa da ADC (Critical Discouse Analysis), apresentada em Fairclough $(2001,2003)$ e Chouliaraki \& Fairclough (1999), configura o modelo teórico que seguimos. ${ }^{2}$ Trata-se de uma abordagem científica transdisciplinar e, sobretudo, bastante adequada para pesquisas voltadas para o estudo da linguagem, tanto na sua exterioridade quanto na interioridade.

De acordo com Fairclough, a proposta da ADC se insere na tradição da "ciência social crítica", comprometida em oferecer suporte científico para questionamentos de problemas sociais relacionados a poder e justiça. Na perspectiva crítica, a linguagem é parte irredutível da vida social, visto que se constitui socialmente na mesma medida em que tem "consequências e efeitos sociais, políticos, cognitivos, morais e materiais", como sugere Fairclough (2003, p. 14). Em seu papel de ciência crítica, a ADC está preocupada com efeitos ideológicos que (sentidos de) textos possam ter sobre relações sociais, ações e interações, conhecimentos, crenças, atitudes, valores e identidades. Em poucas palavras, trata-se de sentidos a serviço de projetos particulares de dominação e exploração, que costumam sustentar uma distribuição desigual de poder.

Como lembram Silva e Ramalho (2008a, p. 269), "a ideia de que problemas sociais podem ser desencadeados e sustentados, assim como superados, por (sentidos de) textos, assenta-se na ontologia do Realismo Crítico", cujo expoente é reconhecido no filósofo contemporâneo Roy Bhaskar $(1978,1998)$. Para o Realismo Crítico, conforme explica Ramalho (2007), o mundo é um sistema aberto, constituído por diferentes domínios (real, actual e empírico), assim como por diferentes estratos. ${ }^{3}$ Os estratos - físico, biológico, social

2. Conforme registro em Silva (2012, p. 226), a Critical Discourse Analysis (CDA) floresce na Europa e chega ao Brasil, em 1993, pelo trabalho pioneiro de Izabel Magalhães, na Universidade de Brasília (UnB), com a sigla de ADC, o que marca a entrada do "grupo de Brasília" no cenário dos estudos do discurso.

3. Os termos originais em Bhaskar (1998) são real, actual e empirical. No contexto do presente estudo, o termo "actual" é mantido em inglês, a exemplo das traduções brasileiras atuais. 
e semiótico - envolvem estruturas distintivas e mecanismos gerativos que se situam no domínio do real, os quais, quando são ativados simultaneamente, causam efeitos imprevisíveis nos demais domínios da vida social. Resulta que a relação existente entre os estratos é de interdependência causal, uma vez que a operação de qualquer mecanismo gerativo dos diferentes estratos é sempre mediada pela operação simultânea de outros, de forma tal que não são redutíveis a um e sempre dependem (e internalizam traços) de outros. Por isso, como esclarece Sayer (2000, p. 11), ainda que não haja necessidade de voltar ao estrato da biologia, da física ou da química para investigar fenômenos sociais, isso não significa que os primeiros não tenham efeito sobre a sociedade e vice-versa (Silva e Ramalho, 2008a).

Considero relevante destacar a interação da Análise de Discurso Crítica (ADC) com a Linguística Sistêmico-Funcional (LSF), duas vigas-mestras que sustentam a edificação epistemológica do estudo ora apresentado. Parto do princípio de que a relação linguagemsociedade não é externa, mas, sim, interna e dialética, de modo que processos linguístico-discursivos são, em parte, fenômenos sociais e, em parte, fenômenos cognitivos, ambos dispostos em uma espécie de estrada de mão dupla por onde transitam o discurso como prática social (exterioridade) e a gramática (interioridade do sistema linguístico), analogia sugerida em Silva (2012). A essa bidirecionalidade associarei, mais adiante, o construto teórico que proponho, baseado na proposta de Halliday (1994), como "mandala da gramática da experiência”.

\subsection{Linguística Sistêmico-Funcional}

A Linguística Sistêmico-Funcional (LSF) configura-se como uma teoria social, uma vez que envolve o estudo da língua não apenas em termos estruturais (interioridade do sistema), mas, sim, a partir dos significados da linguagem como meio de comunicação entre os homens, levando em conta a interação entre esses e a sociedade na qual se encontram. Essa integração de língua, linguagem e sociedade, como bem observam Barbara e Macedo (2009, p. 91), coloca a LSF 
num contexto pós-moderno, diferente daquele tradicionalmente ocupado pela Linguística.

De acordo com Halliday (1994), dois propósitos gerais subjazem a todos os usos da linguagem: entender o contexto (função ideacional), bem como atuar nele com os outros (função interpessoal). Sugere o referido linguista que esses dois propósitos não seriam alcançados se não existisse o texto como mensagem organizada, em termos de estrutura interna, para alcance de propósitos sociais (função textual). Trata-se, aqui, de um enfoque de estrutura (gramática) a partir de significados funcionais da linguagem.

Enquanto a função constitui uma propriedade fundamental da linguagem, a gramática pode ser compreendida como "sistema de opções disponíveis na língua", sendo que "o falante ou escritor realiza suas escolhas dentro deste sistema, não no vazio, mas no contexto das situações de fala”, conforme enfatiza Halliday (1975, p. 147). Assim, as opções formais dentro das estruturas linguísticas têm significados contrastantes e as seleções de forma são sempre significativas em nível de discurso. Além disso, sempre de acordo com Halliday, os textos representam simultaneamente aspectos do mundo físico, social e mental.

Como registrado em Silva (2009, p. 66), é nessa perspectiva que Halliday (1994) aponta três macrofunções simultâneas da linguagem, passíveis de serem identificadas em textos: a ideacional (enfoque na oração como processo); a interpessoal (enfoque na oração como ato de fala); e a textual (enfoque na oração como mensagem). Em seu diálogo com a LSF, sugere Fairclough (2003) que um texto, além de envolver simultaneamente as funções ideacional, interpessoal (identitária e relacional) e textual, deve ser visto sob o prisma de três tipos de significados da linguagem, ou seja, como ação (por meio de um gênero), representação (por meio de um discurso) e identificação (por meio de um estilo), que são os três elementos de ordens de discurso.

Nessa perspectiva, cada ordem de discurso encerra gêneros discursivos característicos, que articulam discursos e estilos de maneira relativamente estável num determinado contexto socio-histórico 
e cultural. Observe-se que gêneros, discursos e estilos constituem elementos de ordens do discurso, diferentes de nomes e orações, que são elementos de estruturas linguísticas. Sempre de acordo com Fairclough, as ordens do discurso podem ser vistas como organização e controle da variação linguística, o que pode ser investigado, a meu ver, a partir da transitividade da linguagem dentro da proposta hallidayana, tema que será enfocado mais adiante. A seguir, enfocar-se-á o que vem a ser etnografia crítica, bem como ecolinguística.

\section{Entre a Etnografia Crítica e a Ecolinguística}

Esta seção envolve dois tópicos que se coadunam, ainda que de maneiras distintas. Enquanto a etnografia crítica é uma abordagem metodológica, a ecolinguística constitui, dentro da linguística, uma corrente teórica crítica que busca aprofundar o estudo da relação entre língua e meio ambiente.

\subsection{Etnografia crítica}

O termo etnografia crítica nomeia uma abordagem metodológica equivalente a um tipo de reflexão que examina ação, cultura e conhecimento. ${ }^{4}$ Trata-se de um processo reflexivo de escolha entre alternativas conceptuais e julgamentos de significados e métodos para desafiar a investigação, o policiamento e outras formas de atividades humanas. Esta é a razão pela qual é apresentada em primeiro lugar, nesta seção, como uma espécie de guia para se discutir questões culturais voltadas para o mundo físico, biológico e social, sobretudo, concernentes à linguagem humana. Nas palavras de Jim Thomas (1993, p. 14):

4. Do ponto de vista da linguística histórica, o termo etnografia vem do grego ethnos (substantivo referente a grupos de pessoas não-gregas) + grafo (verbo referente à ação da escrita). Daí o significado etimológico de etnografia: escrever sobre os outros. 
Toda a experiência cultural exige uma leitura interpretativa. Aprender as regras adequadas para codificação e decodificação do significado das mensagens implica o desenvolvimento de uma forma não só para aprender a língua, mas também para compreender os múltiplos contextos nos quais algumas línguas são necessárias, ou irrelevantes, ou ameaçadas.

É com base nas ideias destacadas na citação acima que Thomas aponta caminhos de uma crítica sem amarras (unleashing critique). Os investigadores críticos devem partir da premissa de que toda vida cultural constitui uma constante tensão entre controle social e resistência. Trata-se de uma tensão que se reflete no comportamento humano, na interação cotidiana, nas relações interpessoais, nos sistemas normativos, bem como nos recursos que formam parte de uma dada cultura.

Por um lado, sugere Thomas que a etnografia crítica deve levar em conta inclusive eventos aparentemente mundanos, ainda que repulsivos, e os descrever de modo a expor processos mais amplos de controle social, que podem funcionar como formas de 'domestificação' de poder. Poderíamos ilustrar essa questão evocando, por exemplo, problemas sociais, tais como o tráfico de mulheres para prostituição, assim como a venda de órgãos humanos. Outra situação que se aproxima de formas naturalizadas de 'domestificação' de poder encontra-se configurada no programa recente do governo federal brasileiro, concernente ao combate às drogas, que legaliza o recolhimento e a internação compulsória de pessoas em situação de rua para tratamento de saúde. Como já discuti em Silva (2007, p. 51):

Seja nos meios acadêmicos, ou nos noticiários de modo geral, encontra-se uma serie de vocábulos que estão incorporados nas nossas práticas discursivas de maneira naturalizada, tais como "riqueza e pobreza", "igualdade e desigualdade", "inclusão e exclusão". Mais que pistas linguístico-discursivas que remetem a uma ideia de oposição, essas formas de expressão significam representações que fazem parte da nossa memória social. 
Meu propósito, também aqui, no contexto do presente estudo, é refletir sobre práticas sociais que, por meio do recurso linguístico das nominalizações, costumam camuflar processos, com o apagamento dos respectivos agentes. Destaco isso com vistas a contribuir para a conscientização sobre efeitos de práticas discursivas naturalizadas por um processo de domestificação. Como adverte Thomas (op. cit., p.8) "nosso problema é que quando nos acostumamos com nossa coleira intelectual, passamos a ser domesticados". ${ }^{5}$ Essa observação permite evocar um problema multifacetado: formas de vida em desequilíbrio, tanto ambiental quanto social e cultural, que remetem a questões próximas ao binômio "inclusão e exclusão". Isso, se observarmos, sob uma lupa ecológica, o mundo que nos rodeia. No contexto brasileiro, por exemplo, ainda que não se queira enxergar, em tempos recentes temos assistido ações governamentais que vão desde a mudança de leito de rios (como o projeto de transposição do rio São Francisco) até a desapropriação de terras indígenas, em favor da construção de usinas hidroelétricas. Pois bem, de acordo com Couto (2007, p. 45), "um dos efeitos de qualquer disciplina ecológica é juntar e não separar", o que nos permite ponderar que decisões políticas dessa magnitude, ao beneficiar uma parte da população com o conforto da energia e irrigação, põem para fora de um dado território, apartam e excluem não só uma comunidade ribeirinha, ou uma nação indígena, mas também uma cultura, pelo rompimento da relação entre o homem e o meio ambiente e, o que mais cabe ressaltar, grupos cujos direito à terra são violados em favor de uma sociedade domesticada.

\subsection{Ecolinguística}

A ecolinguística pode ser definida, nas palavras de Couto (2009, p. 126), como "o estudo das relações entre língua e meio ambiente". Desde essa perspectiva, Couto (2007, 2009) vemse dedicando ao estudo comparativo de diferentes disciplinas e

5. Trad. livre de: "Our problem is that we are accustomed to our intelectual leash; we become domesticated" (Thomas, 1993, p. 8). 
escolas, o que lhe permitiu aprofundar seu interesse de pesquisa sempre voltado para três esferas inter-relacionadas - território, população e língua -, bem como enfatizar a interação 'ecológica' existente entre o linguístico e o social, o que é sintetizado em sua proposta teórica mais recente de uma linguística 'ecossistêmica', relacionada à seguinte tríade:

- ecossistema natural da língua (base ontológica de tudo o que se refere à língua)

- ecossistema mental da língua (lado cognitivo, meio ambiente mental da língua)

- ecossistema social da língua (o todo formado pela língua e a sociedade)

Sempre de acordo com as explicações do referido autor, o que se busca é mostrar, de modo específico, como ocorre a variação no interior do sistema da língua, em razão da sua natureza sistemática. Pode-se afirmar que se trata de um modelo que guarda uma relação de semelhança com a proposta de Halliday (2003, p. 4) para quem a língua, enquanto sistema físico, biológico e social, constitui um recurso de construção de significados, bem como de interpretação de outras formas de semioses em contextos sociais, razão pela qual pode ser considerada como um sistema semiótico de nível superior, que abarca outros sistemas em uma ordem de complexidade ascendente:

1. 1. o sistema físico (o que corresponderia, em parte, ao 'ecossistema natural' da língua)

2. 2. o sistema biológico (de 'vida', com o físico e o cognitivo do 'ecossistema mental')

3. 3. o sistema social (equivalente ao 'ecossistema social' no binômio língua e sociedade)

Com relação ao sistema social na proposta hallidayana, comentam Ghio e Fernández (2008, p. 14), que se trata de um conjunto de sistemas biológicos (formas de vida, com um traço adicional que pode ser denominado de 'valor'. Para as duas linguistas argentinas , o sistema social corresponderia a um sistema de terceira 
ordem de complexidade, sendo ao mesmo tempo: social, biológico e físico. Isso, em consonância com a seguinte ponderação colhida em Halliday (2003, p. 2): "podemos pensar que um sistema semiótico pertence a uma quarta ordem de complexidade, porque é, ao mesmo tempo, semiótico e social, biológico e físico". Essa seria a razão pela qual o significado se constrói socialmente, ativa-se biologicamente e se encontra em intercâmbio através de caracteres físicos. Na esteira do pensamento de Halliday, assim como na proposta da linguística 'ecossistêmica' de Couto, pode-se ponderar, ainda, que a língua como prática social (discurso) constitui, entre todos os sistemas semióticos, a principal fonte de comunicação e, por conseguinte, de poder em termos de seu potencial infinito. Pode-se afirmar que na concepção de Couto seria uma forma de poder ligada a uma espécie de 'ideologia' ecológica.

\section{A mandala da gramática da experiência: por uma visão crítica entre o social e o linguístico}

Com o propósito de aproximar respostas para questões sociais que se situam nas fronteiras entre discurso do ecologismo e ecologia humana, busco traçar, a partir desse momento, um percurso de discussão balizado pela rota da transitividade da linguagem. Como mencionado anteriormente, a transitividade é pertinente à macrofunção ideacional, voltada para a gramática da experiência, a qual reflete as representações do mundo do falante, o que envolve, na minha concepção, os sistemas físico, biológico e social ( $c f$. Halliday, 2003), bem como os 'ecossistemas' natural, mental e social da língua (cf. Couto, 2007).

A função ideacional - enquanto componente principal do significado no sistema linguístico - consiste, em parte, na expressão do conteúdo, da "gramática da experiência" do falante/escritor conforme sugerem Halliday e Matthiessen (2004), no que concerne ao mundo exterior, físico (do fazer), ao mundo das relações abstratas (do ser), bem como ao mundo interior, cognitivo (do sentir), ou seja, o mundo 
da consciência, o que será explanado a partir da Figura 1: Mandala da Gramática da Experiência, que apresento a seguir.

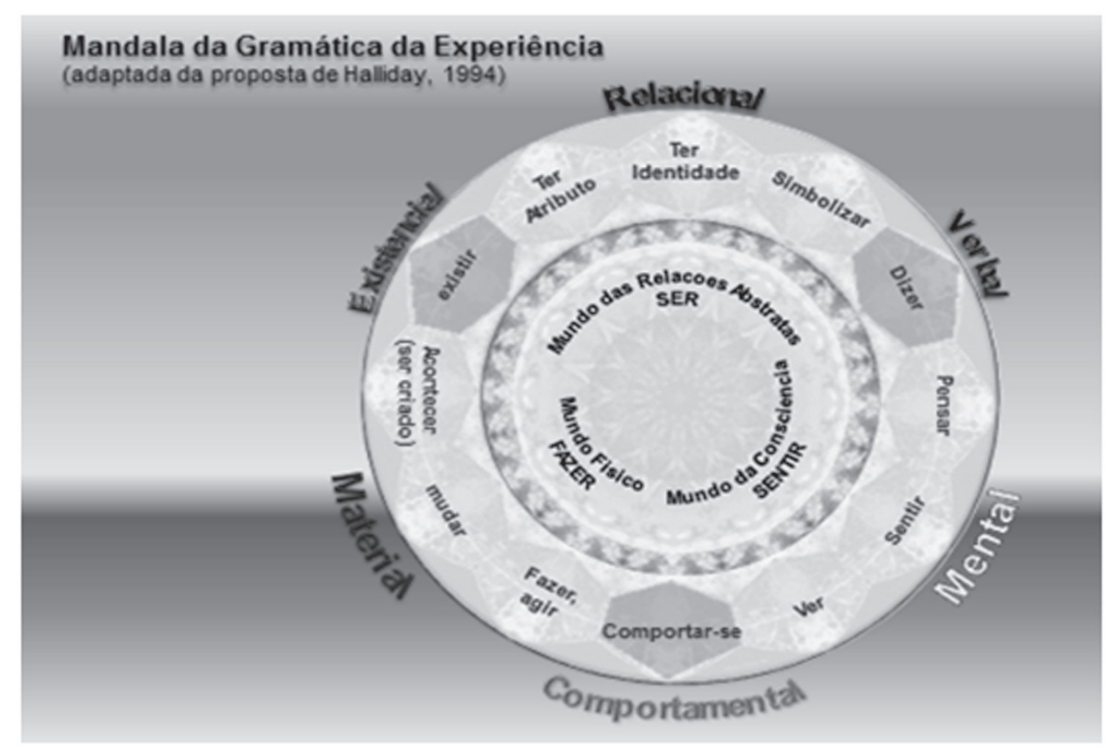

Figura 1: Mandala da Gramática da Experiência

A Figura 1 sintetiza um modelo teórico que apresento em Silva (2011). Trata-se de uma analogia relacionada ao esquema ilustrativo proposto por Halliday (1994) e explicitado em Halliday e Mathiessen (2004: 172) ${ }^{6}$, que redireciono a tipos de processo em português, a partir de outra construção metafórica, nos seguintes termos:

A Figura acima, batizada por mim como "Mandala da Gramática da Experiência", configura uma aproximação metafórica da energia emanada dos centros geradores de nosso mundo conceptual e

6. Com base na ideia de um spectrum de cores, Halliday (1994) e Mathiessen (2004, p. 172) sugerem, para tipos de processos da língua inglesa, uma aproximação metafórica de um modelo de gramática processual à semelhança do mundo das cores. Os processos materiais, mentais e relacionais corresponderiam às cores primárias (puras), enquanto os processos verbais, comportamentais e existenciais estariam próximos das cores secundárias (mescladas). 
linguístico caracterizado, conforme a proposta hallidayana, por seis tipos de processos (indicados, acima, ao redor da mandala) material, mental, relacional, comportamental, verbal e existencial -, cujos significados prototípicos, no interior dos símbolos sextavados, constituem pistas tanto para análise léxico-gramatical quanto semântico-discursiva. Isso, juntamente com outros dois componentes da transitividade: participantes (tais como ator, agente, meta, beneficiado ou afetado entre outros), explicitados ou não, e circunstâncias (advérbios), possíveis de serem identificados na superfície de um texto. (SILVA, 2011:14)

Enquanto os três primeiros processos citados - materiais, mentais e relacionais - são considerados básicos, os três últimos comportamentais, verbais e existenciais - são considerados secundários, uma vez que se encontram mesclados, em termos de significado(s), justamente pela proximidade das fronteiras de sentido intercaladas pelos processos básicos. De acordo com Halliday e Matthiessen (2004: 173), trata-se de uma mescla resultante da preservação de traços semânticos de processos vizinhos, o que é referido como princípio linguístico de 'indeterminação sistêmica', associado à variação funcional de sentido que formas verbais podem apresentar conforme o contexto de realização.

Sugerem os dois autores que nosso mundo experiencial é altamente indeterminado, razão pela qual é construído em nível de gramática dentro de um sistema de tipos de processos. Além disso, os processos de natureza existencial (existir, assim como ter, no sentido de haver, inclusive ocorrer e até mesmo dar, que configuram um uso bem característico do português brasileiro), os de natureza verbal (todos os verbos dicendi ou do dizer) e os de natureza comportamental (intransitivos que não implicam volição) ocorrem de maneira menos recorrente, sendo menos representativos, portanto, em eventos comunicativos (textos).

Na chancela da proposta hallidayana, pondero que a mandala da gramática da experiência reflete, de maneira parcial, representações do mundo do falante (físico, mental e social). Isso, porque a figura acima compreende apenas um dos componentes da transitividade: 
os processos verbais. Compõem a transitividade da linguagem, além desses processos propriamente ditos (grupos verbais), os participantes do processo (grupos nominais) e as circunstâncias (grupos adverbiais). ${ }^{7}$ Vale aqui ressaltar que um período (complexo oracional), formado por orações de tipos de processos vinculados a mundos diferentes (físico, relacional abstrato, cognitivo), pode envolver contribuições funcionais distintas em termos de construção textual. Como já mencionei anteriormente, as opções formais dentro das estruturas linguísticas têm significados contrastantes e as seleções de forma são sempre significativas em nível de significados representacionais do discurso.

Ao defender que a função constitui propriedade fundamental da língua, Halliday permite-nos identificar, a partir da macrofunção ideacional, que os processos de transitividade aproximam discurso e gramática, uma vez que esta última possibilita o acesso a um dado momento discursivo, por meio da análise que se pode fazer da organização interna da língua em uso, ou seja, do discurso como prática social. No contexto do presente trabalho, o foco de interesse recai nas práticas sociais que podem ser reconhecidas como discursos do ecologismo, ao lado da ecologia humana, o que nos permite identificar escolhas linguístico-discursivas, assim como outras formas de semiose, o que inclui a língua e o meio ambiente (ecolinguística). Isso, desde o mundo interior das relações abstratas (ser), passando pelo mundo físico (ações materiais) das práticas sociais (convivência, variação e mudanças, adaptações) até o mundo da consciência (sentidos), o que guarda relação com o comportamento humano (em termos de condutas, como a ética), pela necessidade de preservação da vida (o que inclui o entorno).

7. Cabe lembrar que, no português, um participante pode não aparecer explicitamente mencionado na superfície textual/ discursiva, mas pode ser identificado pela desinência número-pessoal do verbo que marca a sua presença de maneira implícita. 


\section{Do conceito de ecologia humana à política de desenvolvimento sustentável}

Esta seção envolve três momentos. No primeiro, traço uma breve caracterização da ecologia humana como ciência. Em seguida, apresento três correntes do ecologismo que se destacam em termos históricos. A última seção é dedicada à trajetória do denominado "desenvolvimento sustentável", movimento de conscientização política, cujas raízes começaram a se fortalecer pela seiva de correntes sociais, que escorreu e se esparramou pelo mundo como uma reação ao crescimento econômico.

\subsection{Ecologia humana}

A ecologia humana é um ramo da ciência que tem como objeto de estudo a relação do ser humano com seu ambiente natural. Nessa perspectiva, guarda relação de proximidade com disciplinas de diversos campos sociais em termos de uma busca constante da interação do ser social com o mundo que o rodeia, desde a descoberta do entorno, o que inclui a própria pessoa (mundo do ser), a evolução do pensamento (mundo da consciência) e, de modo especial, a necessidade preservação da vida (mundo biológico, físico).

Em tempos atuais, trata-se de uma ciência que demanda investigações cada vez mais necessárias, sobretudo, diante de um intercâmbio ecologicamente desigual entre o homem e a natureza, talvez a razão maior pelos desastres e catástrofes naturais que assistimos nos últimos tempos. Por outro lado, como bem observa Alier (2007, p. 36), "à medida em que se expande a escala da economia, mais resíduos são gerados, mais os sistemas naturais são comprometidos, mais se deterioram os direitos das gerações futuras, mais os conhecimentos dos recursos genéticos são perdidos”. Pode-se ponderar que, enquanto analistas críticos do discurso, precisamos investigar com profundidade, na trilha do ativismo reflexivo da ecolinguística, além da materialidade linguístico-discursiva e sob a lupa da etnografia crítica, práticas sociais 
com vistas a denunciar ações de injustiça, ou em condições propícias, apontar práticas discursivas que beneficiem diferentes formas de ser, de pensar e de usar a natureza.

\subsection{Três correntes principais voltadas para movimentos ambientalistas}

Esta subseção está dedicada a uma revisão, ainda que sucinta, de três vertentes ambientalistas apontadas como - "culto ao silvestre", "evangelho da ecoficiência" e "ecologismo dos pobres". Por um lado, trata-se de correntes entrelaçadas, resultantes, em princípio, de um movimento surgido como reação ao crescimento econômico, como sugere Martínez Alier (2007, p. 22), para quem "tais vertentes são como canais de um único rio, ramificações de uma grande árvore ou variedades de uma mesma espécie agrícola”. Por outro lado, conforme menciona o referido autor, tem-se presenciado, de fato, nos últimos vinte anos para cá, o surgimento de uma economia ecológica paralela a uma economia política.

Em termos cronológicos, a primeira corrente, que ficou conhecida como "culto ao silvestre" estaria identificada pelos seguintes atributos: respeito à vida selvagem, defesa da natureza intocada, retórica de apelo aos valores utilitaristas (mas com vistas à preservação para o uso mercantil), respeito à sacralidade da natureza e pelo papel do sagrado/mágico em algumas culturas. Sempre de acordo com Alier, pode-se associar esse momento à Convenção da Biodiversidade, no Rio de Janeiro (1992), bem como à criação da Lei de Espécies em Perigo (EUA, 1960).

Quanto à corrente batizada por Alier (op.cit, p. 26) como "credo - ou evangelho da ecoficiência", sua atenção estaria voltada para impactos de natureza ambiental, situações de risco à saúde, resultante de urbanização, bem como de atividades industriais e, inclusive da agricultura moderna. Informa Alier que se trata de uma corrente nascida na Europa por volta de 1990. Além de se destacar das outras duas pela sua posição como defensora da economia moderna, a referida corrente apresenta as seguintes características: alerta com 
relação aos efeitos do crescimento econômico; preocupação com os impactos da produção de bens e com o manejo sustentável (ou uso prudente) dos recursos naturais e com o controle da contaminação; enfoque no "capital natural" e nos "serviços ambientais" e não na natureza em si; busca de soluções de ganhos econômicos e ganhos ecológicos; gestão científica dos recursos naturais para garantir sua utilização permanente. Entre as escolhas vocabulares dos representantes dessa segunda corrente, merece destaque termos como 'capital natural', 'controle da contaminação' e 'serviços ambientais', bem como a forma verbal 'bioindicar', associada a fenômenos ligados ao desaparecimento de aves, utilizadas em minas de carvão com a função de cobaias, cuja resistência às condições locais servia para indiciar o grau de gases venenosos emanados naqueles ambientes. Isso evoca o que discuti anteriormente com base em Thomas (1993), ou seja, quanto a processos mais amplos de controle social, que podem funcionar como formas de 'domestificação' de poder.

Comenta Alier (2007, p. 27) o seguinte:

“a extinção de aves, rãs ou borboleta 'bioindica' problemas, tal como a morte de canários nos capacetes dos mineiros de carvão. Contudo, essas espécies, enquanto tais, não possuem direito indiscutível à vida. Esse credo é atualmente um movimento de engenheiros e economistas, uma religião da utilidade e da eficiência técnica desprovida da noção do sagrado".

Nessa perspectiva, cabe mencionar, ainda, que condutas dessa natureza são movidas por ideologias que nos podem domesticar através da construção de significados e justificativas, para nossas próprias ações e ações dos outros. Trata-se, na situação acima destacada, de formas 'naturalizadas' de prática social de profissionais que, em razão de uma legitimidade de procedimentos técnicos assumidos, regidos por princípios ideológicos e empresariais, estes, por sua vez, voltados para um 'capital natural' que alicerça uma política econômica por meio de ações de injustiças humanas e atos de inequidade, recategorizados, ou melhor, disfarçados em nominalizações, tais como 'serviços ambientais'. 
Quanto ao "ecologismo dos pobres", nas palavras de Alier (2007, p. 34), "sua ética nasce de uma demanda por justiça social contemporânea entre os humanos". Essa corrente tem sua origem em conflitos ambientais em nível local, regional, nacional e global, causados pelo crescimento econômico e pela desigualdade social. Parece tratar-se de um vigoroso movimento de justiça ambiental, que surge como um alerta face ao deslocamento geográfico das fontes de recursos, por um lado e como denúncia com relação às áreas de descarte de resíduos por meio de ações concretas de países industrializados. Seu lema, baseado na justiça ambiental do sustento da sobrevivência humana, surge nos Estados Unidos em 1996 e se estende a países industrializados em suas demandas de matériasprimas. Enfim, o eixo principal do "ecologismo dos pobres" é movido pelo interesse material pelo meio ambiente como fonte de condição para subsistência.

\subsection{O desenvolvimento sustentável}

O termo 'desenvolvimento sustentável' é enfocado, no âmbito do presente estudo, conforme o sentido consolidado durante a Conferência das Nações Unidas sobre Meio Ambiente, evento conhecido também como Rio-92. Em poucas palavras, trata-se de um conceito que expressa a busca de superação do dilema existente entre proteção ambiental e desenvolvimento econômico.

Com esse sentido, o desenvolvimento sustentável inaugurou, já em 1972, uma agenda política internacional de compromissos, planejada para suplantar problemas ambientais, por ocasião da Conferência das Nações Unidas sobre Meio Ambiente Humano, realizada na cidade de Estocolmo. Tais compromissos, reafirmados na Rio-92, foram analisados e avaliados em Johanesburgo, África do Sul, no evento conhecido como Cúpula Mundial sobre Desenvolvimento Sustentável, em 2002, ano em que mais de cem chefes de Estado discutiram a necessidade de implantação de metas voltadas para erradicação da pobreza e promoção da saúde, bem como defesa da biodiversidade, entre outros temas. (ABRANTES, 2012) 
$\mathrm{Na}$ Rio +20 , que corresponde à edição mais recente da Conferência das Nações Unidas sobre Desenvolvimento Sustentável, além da discussão de ações adotadas por países membros, foram estabelecidas, em 2012, diretrizes balizadas por três pilares - social, econômico e ambiental - a serem avaliados e, em condições propícias, seguidos nos próximos anos de vida social no planeta Terra. Os três pilares, bem como as condições de vida social, só serão avaliados em uma edição do evento que só vai acontecer outra vez daqui a vinte anos.

Se buscarmos traçar um paralelo entre esses três pilares, poderemos identificar tendências contrastantes nas promessas de ações futuras, pertinentes a cada um deles no âmbito da conferência das Nações Unidas, proferida recentemente em prol do desenvolvimento sustentável, em meio à presença de lideranças de inúmeras nações. Grosso modo, conforme já cometei em Silva (2012), resulta que o meio ambiente, o ecossistema, a biodiversidade, a chuva ácida, o uso de energia suja - bem como a água que corre por todos os rios do planeta, antes de desembocar nos sete mares - continuam a ser enfocados como tópicos que sinalizam, ora uma bandeira para ativistas, ora uma promessa de agenda de compromissos político-econômicos, diante dos apelos direcionados aos países ricos, que não querem repartir recursos que lhes sobram, ainda que tão cientes de questões complexas, tais como a pobreza do presente ou a escassez de água e de alimento no futuro próximo. Como adverte Thomas (1993, p. 4), "o problema, portanto, não é a adesão a um determinado conjunto de premissas ideológicas, mas, sim, deixar de reconhecer a distorção que essas preferências ideológicas possam produzir em nossa vida cotidiana". ${ }^{8}$

Por outro lado, como bem observam Araújo e Fraga (2013, p.11), "o discurso predominante no evento do Rio +20 encontrase fortemente marcado pela preocupação voltada para o crescimento econômico, que é apresentado como via para soluções das mazelas da sociedade e da natureza". De acordo com a análise crítica das duas

8. Tradução livre: The problem, therefore, is not so much that we adhere to a given set of ideological premises, but rather that we fail to recognize the distortion our ideological preferences produce in our everyday life (Thomas, 1993, p.9). 
pesquisadoras, o meio ambiente é relegado a um segundo plano diante das demandas prioritárias de cunho social e econômico.

\section{Considerações finais}

À guisa de conclusão, uno as pontas dos enlaces teóricos que procurei amarrar e, ao mesmo tempo, desdobrar de maneira reflexiva, ao longo de percursos guiados por significados de discursos do ecologismo em uma nova roupagem de práticas sociais de natureza ideológica. Trata-se de significados identificados por meio da intertextualidade que perpassa, por sua vez, o tema voltado para questões ambientais, patente na interdiscursividade dos movimentos ecológicos que visam mais aos lados econômico e político, em termos de 'articulações particulares', que ao bem estar geral da humanidade. Conforme bem observa Fairclough (2010, p. 234), “a interdiscursividade de um texto é um aspecto de sua intertextualidade, uma questão pela qual a intertextualidade nos permite identificar em que tipos de gêneros, discursos e estilos encontra-se delineada e como funciona em termos de articulações particulares". ${ }^{9}$

Desde a perspectiva da Análise de Discurso Crítica, conjugada com a proposta da Linguística Sistêmico-Funcional, busquei enfocar discursos do ecologismo e da ecologia humana, com ênfase na mandala da gramática da experiência, como suporte teórico reflexivo, bem como por uma visão crítica entre o social e o linguístico, o que se estendeu às contribuições da Ecolinguística. Entre as ideias dos estudiosos enfocados ao longo do artigo, destaco a seguinte reflexão de Couto (2009, p. 138), a partir do ponto de vista de sua Ecolinguística:

De acordo com Halliday (2001), os discursos tecnocrático, burocrático e científico são herméticos, com o que os assuntos se tornam obscuros. Uma vez que "são obscuros, não devemos ter esperança de os entender,

9. Trad. Livre: the interdiscursivity of a texts is an aspect of its intertextuality, a question of wich genres, discourses and styles it draw upon, and how it works them into particular articulations. 
de modo que a solução deve ficar com os especialistas" (cf. Halliday, op cit. p. 19). Em parte isso se deveria, segundo ele, à gramática nominalizadora e metafórica do século XX./.../. A proposta de Halliday sugere que "a nominalização foi funcional para a evolução da ciência experimental, possibilitando o desenvolvimento de taxionomias técnicas e desvelando as relações existentes entre processo, mas não é adequada para representar a visão de mundo mais relativística que está emergindo da ciência moderna porque representa um mundo de coisas, não de processos”. Nominalizações como perda de habitat, extinção de espécies e destruição da floresta tropical omitem o agente, o que ocultaria a culpa de quem causa tudo isso.

Resulta que, no estudo aqui levado a cabo, entre as expressões mais frequentes, que marcam contextos discursivos e práticas sociais históricas, em nível global - tais como as advindas de movimentos ecológicos ou ambientalistas, sob rótulos do tipo "culto ao silvestre", "evangelho da ecoficiência", "ecologismo dos pobres" até chegar ao recente "desenvolvimento sustentável" -, o que demanda atenção, mais que a interdiscursividade, observada por meio da configuração de convenções discursivas entre os textos, bem como a intertextualidade já esperada, é justamente a maneira como tais expressões aparecem estruturadas. Trata-se de nominalizações criadas, ao que parece, para representar um mundo de 'coisas', não de 'processos', o que permite tornar obscuras novas formas de controle social e de poder.

Recebido em:15/11/2012

Aceito em:20/12/2012 denizelena@gmail.com

\section{Referências bibliográficas}

ABRANCHES, S. Habemus Papirus. Rio de Janeiro: Ecopolítica 2012.

ARAÚJO, C.L. e FRAGA, R.G. O que diz o discurso? Uma análise do discurso da Rio + 20. In: Pesquisa Linguística-Working papers, 11 páginas (mimeo.). Brasília: UnB/Programa de Pós-Graduação em Linguística, 2013. 
BARBARA, L. e MACEDO, C. M. M. Linguística Sistêmico-Funcional para a Análise de Discurso: um panorama introdutório. In: D.E.G da Silva (ed.), Cadernos de Linguagem e Sociedade, vol. 10(1), p. 89-107, 2009.

BHASKAR, R. A realist theory of science. Brighton: Harvester: 1978.

. Philosophy and scientific realism. In: ARCHER, M.; BHASKAR, R; COLlIER, A.; LAWSON, T. \& NORRIE, A. (Ed.). Critical realism: essential readings, p. 16-47. London; New York: Routledge, 1998.

CHOULIARAKI, L.; FAIRCLOUGH, N. Discourse in late modernity: rethinking critical discourse analysis. Edinburg : Edinburg University Press, 1999.

COUTO, H.H. Ecolinguística. In: D.E.G da Silva (ed.), Cadernos de Linguagem e Sociedade, vol. 10(1), p. 125-149, 2009.

FAIRCLOUGH, N. A dialética do discurso. In: I. Magalhães (org.), Discursos e práticas de letramento: pesquisa etnográfica e formação de professores, $\mathrm{p}$. 93-107. Campinas, SP: Mercado das Letras, 2012.

. Critical Discourse Analysis: The Critical Study of Language, $2^{\mathrm{a}}$ ed. Inglaterra: Longman Applied Linguistics, 2010.

. Analysing Discourse: textual analysis for a social research. Londres: Routledge, 2003.

. Discurso e mudança social. I. Magalhães (Coord. da trad. rev. técnica e prefácio. Brasília: Editora Universidade de Brasília, 2001.

GUIO, E y FERNANDEZ, M.A. Linguística Sistémico Funcional. Aplicaciones a la lengua española., $1^{\mathrm{a}}$ ed. Santa Fe: Univ. Nacional del Litoral, Waldhuter Editores, 2008.

HALLIDAY, M. A. K. \& MATTHIESSEN, C. M. I. M. An introduction to Functional Grammar. London: Hodder Arnold, 2004.

. On language and Linguistics, vol. 3 in the Collected Works of M.K. Halliday. Edited by Jonathan Webster Continuum, cap. Introduction: On the "Architecture of Human Language, 2003.

. News ways of meaning: The challenge of applied linguistics. In: Fill \& Mühlhäusler (orgs.), pp. 175-202, 2001.

. An Introduction to Functional Grammar. Londres: Arnold, 1994. 
MARTINEZ ALIER, J. O ecologismo dos pobres: conflitos ambientais e linguagens de valoração. Trad. M. Waldeman. São Paulo: Contexto, 2007.

SAYER, A. Características-chave do Realismo crítico na prática: um breve resumo. Estudos de Sociologia. In: Revista do Programa de Pós-Graduação em Sociologia, vol. 6, n. 2, p. 7-32. Recife: UFPE, 2000.

SILVA, D.E.G. Estudos críticos do discurso no contexto brasileiro: por uma rede de transdisciplinaridade. In: EUTOMIA Revista de Literatura e Linguística, p. 224-243. Recife: UFPE, 2012a. www.revistaeutomia.com.br

- Margens de sentido(s) nas águas textuais e discursivas. In: Revista Universitas Humanas, vol. 9, nº 1, p. 23-30. Brasília: UNICEUB, $2012 \mathrm{~b}$.

Disponível em: http://www.publicacoesacademicas.uniceub.br/index.php/ universitashumanas/article/view/2094

- Representações discursivas da pobreza e discriminação na mídia. In: D.E.G. da Silva, M.C. Leal e M.C.D Pacheco (orgs.), Discurso em questão: representação, gênero, identidade, discriminação, pág. 63-74. Goiânia: Cânone Editorial, 2009.

SILVA, D.E.G. e RAMALHO, V. Análise de discurso crítica: representações sociais na mídia. In: Lara, G. M.P. et alii (orgs.). Análise do discurso hoje, p. 265-291. Rio de Janeiro: Nova Fronteira, 2008a.

SILVA, D.E.G. e RAMALHO, V. Reflexões para uma abordagem crítica dos gêneros discursivos. In: ALED/Revista Latinoamericana de Estudios del Discurso, v. 8 (1), p. 19-40, 2008b.

Disponível em: http://www.portalaled.com/es/reflex\%C3\%B5es-para-umaabordagem-r\%C3\%ADtica-dos-g\%C3\%AAneros-discursivos.

SILVA, D.E.G. Identidades enfraquecidas versus cidadania cultural. In: Sebastien Joachin et alii. Recife: Elógica, 2007.

THOMAS, J. Doing ethnography (Qualitative research methods;v.26). Londres: Sage Publications, 1993. 